\title{
Force Frequency Relationship of the Human Ventricle Increases During Early Postnatal Development
}

\author{
ROB F. WIEGERINCK, ANCA COJOC, CARLO M. ZEIDENWEBER, GUOLIANG DING, MING SHEN, RONALD W. JOYNER, \\ JANET D. FERNANDEZ, KIRK R. KANTER, PAUL M. KIRSHBOM, BRIAN E. KOGON, AND MARY B. WAGNER
}

\author{
Department of Pediatrics [R.F.W., A.C., C.M.Z., G.D., M.S., R.W.J., M.B.W.], and Department of Surgery [K.R.K., P.M.K., B.E.K.], Emory \\ University, Atlanta, Georgia 30322; Children's Healthcare of Atlanta [J.D.F.], Atlanta, Georgia 30322
}

\begin{abstract}
Understanding developmental changes in contractility is critical to improving therapies for young cardiac patients. Isometric developed force was measured in human ventricular muscle strips from two age groups: newborns $(<2 \mathrm{wk})$ and infants $(3-14 \mathrm{mo})$ undergoing repair for congenital heart defects. Muscle strips were paced at several cycle lengths (CLs) to determine the force frequency response (FFR). Changes in $\mathrm{Na} / \mathrm{Ca}$ exchanger (NCX), sarcoplasmic reticulum Ca-ATPase (SERCA), and phospholamban (PLB) were characterized. At CL $2000 \mathrm{~ms}$, developed force was similar in the two groups. Decreasing CL increased developed force in the infant group to $131 \pm 8 \%$ (CL $1000 \mathrm{~ms}$ ) and $157 \pm 18 \%$ (CL $500 \mathrm{~ms}$ ) demonstrating a positive FFR. The FFR in the newborn group was flat. NCX mRNA and protein levels were significantly larger in the newborn than infant group whereas SERCA levels were unchanged. PLB mRNA levels and PLB/SERCA ratio increased with age. Immunostaining for NCX in isolated newborn cells showed peripheral staining. In infant cells, NCX was also found in T-tubules. SERCA staining was regular and striated in both groups. This study shows for the first time that the newborn human ventricle has a flat FFR, which increases with age and may be caused by developmental changes in calcium handling. (Pediatr Res 65: 414-419, 2009)
\end{abstract}

$\mathrm{E}$ xtrapolating pharmacological and surgical therapies from adult studies to pediatric patients is difficult because knowledge of contractility in the young human heart is limited, thus understanding developmental changes in excitationcontraction coupling is critical. In mammalian ventricle, contractility increases with postnatal development $(1,2)$, but few studies have examined age-dependent effects on the forcefrequency relationship (FFR). Several animal studies have found a positive FFR that is not changed with age $(3,4)$. Direct studies of contractility of very young human ventricular strips are limited. Molenaar et al. (5) examined tension development in human ventricular strips from infants $(2.5-35$ mo old $)$ undergoing repair for tetralogy of Fallot (TOF) and report a positive FFR in their cohort. Recently, Cheung et al. (6) measured force frequency curves in children with congenital heart defects using tissue Doppler. They found that children with ventricular septal defects had a decreased force-rate

Received July 24, 2008; accepted November 3, 2008.

Correspondence: Mary B. Wagner, Ph.D., Department of Pediatrics, Emory University, 2015 Uppergate Drive, 336, Atlanta, GA 30322; e-mail: mary.wagner@emory.edu Supported by Grants HL-088488 (M.B.W.) and HL-077485 (R.W.J.) from the National Heart, Lung and Blood Institute, by Grant in Aid 0755537B (M.B.W.) from the American Heart Association Southeast Affiliate, and by financial support from Children's Healthcare of Atlanta.

The first two authors contributed equally to this study. trajectory after bypass surgery whereas neonates, undergoing arterial switch, had a greater decrease of force-rate trajectory.

A flat or negative FFR is a characteristic feature of heart failure $(7,8)$ and is associated with changes in calcium handling proteins, including increased levels of $\mathrm{Na} / \mathrm{Ca}$ exchanger (NCX) $(7,9)$ and decreased levels of sarcoplasmic reticulum (SR), calcium ATPase (SERCA), phospholamban (PLB), and the PLB/SERCA ratio (10-12). NCX is significantly more abundant in the newborn than the adult (1). Furthermore, SERCA is lower in newborn rabbit $(13,14)$ and PLB increases with postnatal age (2). In human ventricle, NCX mRNA and protein levels decreased with age (15) whereas SERCA protein levels increased but mRNA levels were unchanged (16). Alterations of these proteins can modify the ability of the SR to store calcium, which may contribute to the blunted FFR.

We compared the response of newborn $(<2 \mathrm{wk})$ and infant (3-14 mo) ventricular muscle strips to changes in pacing frequency. We show that the newborn human ventricle has a flat FFR that becomes more positive with age. Furthermore, we show alterations in calcium handling protein and mRNA levels with age as well as developmental changes in cellular morphology.

\section{MATERIALS AND METHODS}

Patients. Ventricular tissue was removed as part of the surgical repair for congenital heart defects and divided into two age groups: newborns ( $<2 \mathrm{wk})$ and infants $(3-14 \mathrm{mo})$. The primary diagnosis for the newborns was hypoplastic left heart syndrome (HLHS) with ventricle removed for insertion of a right ventricle to pulmonary artery shunt (Table 1). One sample was left ventricle as noted. The primary diagnosis for the infants was TOF or similar conditions with ventricle obstructing the right ventricular outflow tract removed. The study protocols were approved by the Institutional Review Board of Emory University and Children's Healthcare of Atlanta and determined exempt under 45 CFR 46.101(b) (4).

Isometric contraction measurements. Ventricular tissue was transported to the laboratory in Krebs-Ringer solution containing (in $\mathrm{mM}$ ): $\mathrm{NaCl} 35, \mathrm{KCl}$ 4.75, $\mathrm{KH}_{2} \mathrm{PO}_{4} 1.2, \mathrm{Na}_{2} \mathrm{HPO}_{4} 16$, sucrose 134, $\mathrm{NaHCO}_{3} 25$, glucose 10, HEPES 10, 2,3-butanedione monoxime (BDM) 30, pH 7.4 with $\mathrm{NaOH}$. Tissue was submerged in Tyrode's solution containing $(\mathrm{mM})$ : $\mathrm{NaCl} 148.8$, $\mathrm{KCl} 4.0, \mathrm{MgCl}_{2} 5.3, \mathrm{NaH}_{2} \mathrm{PO}_{4}$ 3.3, HEPES 5.0, $\mathrm{CaCl}_{2} 0.25$, glucose 10 and $\mathrm{BDM} 30, \mathrm{pH} 7.4$ with $\mathrm{NaOH}$. Ventricular strips were trimmed under a dissecting microscope, the width and height at the center of the strip was

Abbreviations: CamKII, calcium/calmodulin-dependent kinase II; CL, cycle length; FDAR, frequency dependent acceleration of relaxation; FFR, force frequency relationship; HLHS, hypoplastic left heart syndrome; NCX, $\mathrm{Na} / \mathrm{Ca}$ exchanger; PLB, phospholamban; SERCA, SR calcium-ATPase; SR, sarcoplasmic reticulum; TOF, tetralogy of Fallot 
Table 1. Patient characteristics

\begin{tabular}{|c|c|c|c|c|c|}
\hline $\begin{array}{l}\text { Patient } \\
\text { number }\end{array}$ & Age & Gender & Race & Diagnosis & Use \\
\hline \multicolumn{6}{|c|}{ Newborns } \\
\hline 1 & $3 \mathrm{~d}$ & M & $\mathrm{C}$ & HLHS & 2 \\
\hline 2 & $3 \mathrm{~d}$ & M & $\mathrm{C}$ & HLHS & 1,2 \\
\hline 3 & $3 \mathrm{~d}$ & M & AA & HLHS & 1 \\
\hline 4 & $3 \mathrm{~d}$ & M & $\mathrm{C}$ & HLHS & 3 \\
\hline 5 & $4 \mathrm{~d}$ & $\mathrm{~F}$ & $\mathrm{AA}$ & TOF & 2 \\
\hline 6 & $4 \mathrm{~d}$ & M & $\mathrm{AA}$ & HLHS & 1,2 \\
\hline 7 & $4 \mathrm{~d}$ & M & $\mathrm{C}$ & HLHS & 2 \\
\hline 8 & $4 \mathrm{~d}$ & $\mathrm{~F}$ & $\mathrm{C}$ & HLHS & 1 \\
\hline 9 & $4 \mathrm{~d}$ & M & AA & HLHS & 3 \\
\hline 10 & $5 \mathrm{~d}$ & M & MR & HLHS & 1,2 \\
\hline 11 & $6 \mathrm{~d}$ & M & $\mathrm{AA}$ & HLHS & 1 \\
\hline 12 & $6 \mathrm{~d}$ & M & $\mathrm{C}$ & HLHS & 4 \\
\hline 13 & $<7 \mathrm{~d}$ & M & $\mathrm{H}$ & HLHS & 1 \\
\hline 14 & $<7 \mathrm{~d}$ & $\mathrm{~F}$ & $\mathrm{C}$ & HLHS & 1 \\
\hline 15 & $<7 \mathrm{~d}$ & M & $\mathrm{C}$ & HLHS & 1 \\
\hline 16 & $<7 \mathrm{~d}$ & M & $\mathrm{C}$ & HLHS & 3 \\
\hline 17 & $7 \mathrm{~d}$ & M & $\mathrm{C}$ & DILV & $4(\mathrm{LV})$ \\
\hline 18 & $7 \mathrm{~d}$ & M & $\mathrm{C}$ & HLHS & 1 \\
\hline 19 & $8 \mathrm{~d}$ & M & $\mathrm{AA}$ & HLHS & 3 \\
\hline 20 & $13 \mathrm{~d}$ & $\mathrm{~F}$ & $\mathrm{C}$ & HLHS & 1 \\
\hline 21 & $14 \mathrm{~d}$ & M & $\mathrm{C}$ & DILV & 1 \\
\hline 22 & $16 \mathrm{~d}$ & M & $\mathrm{AA}$ & HLHS & 1 \\
\hline \multicolumn{6}{|c|}{ Infants } \\
\hline 23 & $3 \mathrm{~m}$ & $\mathrm{~F}$ & $\mathrm{C}$ & DORV & 1 \\
\hline 24 & $3 \mathrm{~m}$ & $\mathrm{~F}$ & NS & TOF & 1 \\
\hline 25 & $3 \mathrm{~m}$ & M & $\mathrm{H}$ & DORV & 1 \\
\hline 26 & $3 \mathrm{~m}$ & $\mathrm{~F}$ & $\mathrm{C}$ & TOF & 3 \\
\hline 27 & $3 \mathrm{~m}$ & M & $\mathrm{C}$ & TOF & 3 \\
\hline 28 & $3.5 \mathrm{~m}$ & M & $\mathrm{C}$ & TOF & 1 \\
\hline 29 & $4.5 \mathrm{~m}$ & $\mathrm{~F}$ & $\mathrm{AA}$ & TOF & 1 \\
\hline 30 & $4.5 \mathrm{~m}$ & $\mathrm{~F}$ & $\mathrm{AA}$ & TOF & 1,3 \\
\hline 31 & $5 \mathrm{~m}$ & M & NS & TOF & 4 \\
\hline 32 & $5 \mathrm{~m}$ & M & NS & $\begin{array}{c}\text { DORV, PS } \\
\text { Down's }\end{array}$ & 1 \\
\hline 33 & $5.5 \mathrm{~m}$ & M & $\mathrm{C}$ & TOF & 3 \\
\hline 34 & $6 \mathrm{~m}$ & $\mathrm{~F}$ & $\mathrm{AA}$ & DORV, PS, & 3 \\
\hline 35 & $6 \mathrm{~m}$ & M & $\mathrm{C}$ & TOF & 1 \\
\hline 36 & $7 \mathrm{~m}$ & $\mathrm{~F}$ & $\mathrm{C}$ & TOF & 4 \\
\hline 37 & $7 \mathrm{~m}$ & M & $\mathrm{C}$ & DCRV, VSD & 1 \\
\hline 38 & $7 \mathrm{~m}$ & M & $\mathrm{AA}$ & TOF & 1 \\
\hline 39 & $7 \mathrm{~m}$ & $\mathrm{~F}$ & $\mathrm{AA}$ & TOF & 3 \\
\hline 40 & $7 \mathrm{~m}$ & $\mathrm{~F}$ & $\mathrm{AA}$ & $\begin{array}{l}\text { VSD, PS, } \\
\text { TGA }\end{array}$ & 1 \\
\hline 41 & $7.5 \mathrm{~m}$ & $\mathrm{~F}$ & $\mathrm{C}$ & TOF, CAVC & 2 \\
\hline 42 & $8 \mathrm{~m}$ & $\mathrm{~F}$ & AA & TOF & 1 \\
\hline 43 & $8 \mathrm{~m}$ & M & AA & PA, VSD & 1 \\
\hline 44 & $9 \mathrm{~m}$ & M & $\mathrm{C}$ & VSD, DCRV & 2 \\
\hline 45 & $10 \mathrm{~m}$ & M & AA & TOF & 2 \\
\hline 46 & $10 \mathrm{~m}$ & M & NS & TOF & 2 \\
\hline 47 & $11 \mathrm{~m}$ & M & AS & VSD, RVOTO & 1 \\
\hline 48 & $12 \mathrm{~m}$ & M & AA & TOF & 1 \\
\hline 49 & $12 \mathrm{~m}$ & M & $\mathrm{AA}$ & $\begin{array}{l}\text { VSD, DORV, } \\
\text { RVOTO }\end{array}$ & 1 \\
\hline 50 & $14 \mathrm{~m}$ & M & $\mathrm{AA}$ & TOF & 1,2 \\
\hline 51 & $14 \mathrm{~m}$ & M & AA & TOF & 1 \\
\hline
\end{tabular}

Race: NS, not specified; C, Caucasian; AA, African American; H, Hispanic; MR, multiracial; AS, Asian diagnosis: HLHS, hypoplastic left heart syndrome; TOF, tetralogy of fallot; DILV, double inlet left ventricle; DORV, double outlet right ventricle; PS, pulmonary stenosis; PA, pulmonary atresia; TGA, transposition of the great arteries; DCRV, double chamber right ventricle; CAVC, complete atrio-ventricular canal; RVOTO, right ventricular outflow tract obstruction; Down's, Down's syndrome. Use: 1, protein; 2 , mRNA; 3, contraction measurements; 4, cell isolation. measured and cross-sectional area was estimated assuming an oval shape. There was no difference in cross-sectional area between the two groups (newborn: $1.0 \pm 0.2 \mathrm{~mm}^{2}, n=7$, infant: $0.8 \pm 0.2 \mathrm{~mm}^{2}, n=7$ ). After transfer to the recording chamber, strips were fixed at one end and connected at the other end by a fine suture to a force transducer. The strip was washed for 30-60 min in oxygenated Tyrode's $(1.5 \mathrm{~mL} / \mathrm{min}$ flow, $1.8 \mathrm{mM} \mathrm{CaCl}$, without BDM) then stimulated at cycle length (CL) $2000 \mathrm{~ms}$ for $30 \mathrm{~min}$ to stabilize and gradually stretched to achieve maximum contraction, which was the length set for the experiment. For the FFR, recordings were made at $30^{\circ} \mathrm{C}$ with pacing at CLs 2000, 1000, and $500 \mathrm{~ms}$.

Expression of calcium handling proteins. Protein preparation and western blot analysis were performed as we previously described (17). Tissue was immediately frozen and stored $\left(-80^{\circ} \mathrm{C}\right)$ until use. Briefly, tissue was homogenized in lysis buffer [20 mM HEPES containing protease and phophatase inhibitors (Sigma Chemical)]. After low speed centrifugation, the supernatant was centrifuged at $200,000 \times g(1 \mathrm{~h})$ to obtain membrane proteins. Protein concentration was measured using the Bradford method (18). Either $3 \mu \mathrm{g}$ membrane or $10 \mu \mathrm{g}$ total protein was separated on a $12 \%$ SDS gel. Each membrane was stained with Ponceau $S$ to confirm equal loading and transfer of proteins. Blots were incubated with antibodies (anti-NCX, anti-SERCA, anti-PLB, Affinity Bioreagents; overnight, $4^{\circ} \mathrm{C}$ ) followed by appropriate HRP-secondary antibody and detection by ECL chemiluminescence (Amersham). Protein bands were quantified by densitometry using ImageJ (National Institutes of Health).

Determination of $\boldsymbol{m R N A}$ levels. Total RNA was extracted using the RNeasy kit (Qiagen) and reverse transcribed to cDNA using a Super Script III kit with random hexamers (Invitrogen). The quality of each sample was confirmed by Agilent 2100 bioanalyzer. Relative quantification of NCX, SERCA, and PLB mRNA levels was performed by real-time RT-PCR (ABI 7500 PCR system) using SYBR Green real-time PCR chemistry (ABI). Specific primers SERCA2a and PLB genes were designed based on GenBank data for human. Predesigned primers for NCX1 were purchased from ABI. The resulting mRNA levels were expressed as a ratio to the level of $18 \mathrm{~S}$ rRNA (19) and samples in duplicate were used.

Immunostaining of isolated ventricular cells. Ventricular myocytes were isolated as previously described (17). Tissue chunks were stirred at $36^{\circ} \mathrm{C}$ for $45 \mathrm{~min}$ in Krebs-Ringer solution containing $300 \mathrm{IU}$ collagenase/mL (type 2, Worthington), $4 \mathrm{IU}$ protease/mL (type XXIV, Sigma Chemical) and $1 \mathrm{mg}$ $\mathrm{BSA} / \mathrm{mL}$, followed by collagenase only until striated cells appeared. Cells were fixed in $4 \%$ paraformaldehyde for $10 \mathrm{~min}$ and stored in $20 \%$ sucrose PBS. Plated cells were permeabilized ( $0.2 \%$ Triton), quenched $(50 \mathrm{mM}$ $\mathrm{NH}_{4} \mathrm{Cl}$-PBS-Solution), blocked and incubated with primary antibodies overnight (NCX, 1:150 and SERCA, 1:200, ABR) followed by secondary antibody incubation. Cells were imaged using confocal microscopy (Olympus Fluoview).

Statistical analysis. Contractile parameters, mRNA levels and protein levels are reported as mean \pm SEM and significance was evaluated by $t$ test or two-way repeated measures ANOVA, followed by Turkey test. $p<0.05$ indicates statistical significance.

\section{RESULTS}

FFR in newborn compared with infant ventricular strips. Table 1 summarizes patient characteristics. Figure $1 A$ shows steady-state developed force for a newborn strip ( $4 \mathrm{~d}$, top) and for an infant strip (3 mo, bottom), with decreasing pacing CL from 2000 to $500 \mathrm{~ms}$. As CL is shortened, developed force does not increase in the newborn but does increase in the infant. The average developed force in newborn muscle strips $(n=7)$ was $1.3 \pm 0.3,1.4 \pm 0.3$ and $1.1 \pm 0.3 \mathrm{mN} / \mathrm{mm}^{2}$ at CLs 2000, 1000, and $500 \mathrm{~ms}$, respectively, and in infant muscle strips $(n=7)$ was $0.9 \pm 0.4,1.2 \pm 0.6$, and $1.7 \pm 0.9$ $\mathrm{mN} / \mathrm{mm}^{2}$. In the infants, developed force at CL $500 \mathrm{~ms}$ was significantly $(p<0.05)$ larger compared with CL $2000 \mathrm{~ms}$. For ease of comparison, we normalized developed force in each strip to that measured at CL $2000 \mathrm{~ms}$. Figure $1 B$ shows the overlay of the contractions for the different CLs. Developed force is not increased at faster stimulation rates in the newborn (top), resulting in a flat FFR. In contrast, the infant has a robust, positive FFR, and this is shown in the summary 

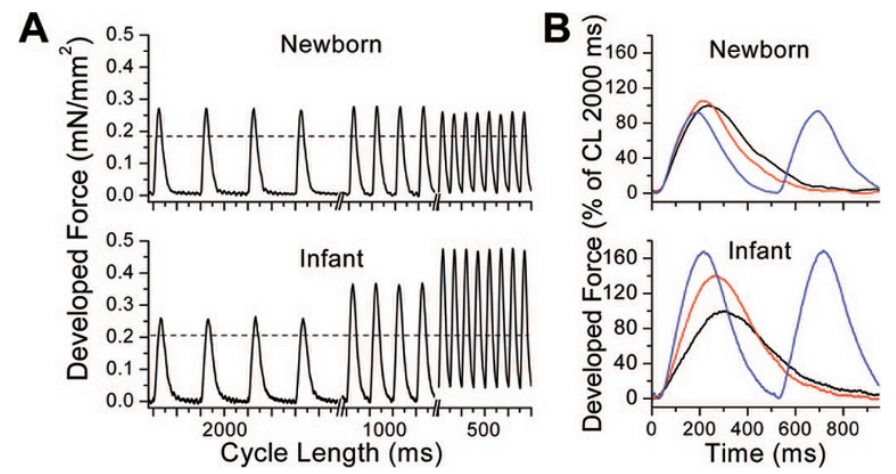

Figure 1. Contractions measured in ventricular tissue strips. A. Developed force from a newborn (4-d-old, top panel) and an infant (3-mo-old, bottom panel) strip. The pacing cycle length (CL) decreased from 2000 to 1000 and $500 \mathrm{~ms}$. Steady state contractions are shown and the dashed line indicates the amplitude of developed force at CL $2000 \mathrm{~ms}$. B. Developed force as in A, but normalized to the amplitude at CL 2000 ms (black line) with CL $1000 \mathrm{~ms}$ (red) and CL $500 \mathrm{~ms}$ (blue) overlaid.

data in Figure $2 A$. At CL $500 \mathrm{~ms}$, the percent increase in developed force is significantly greater in infant compared with newborn. Despite the flat FFR in the newborn, there is a large increase in frequency dependent acceleration of relaxation (FDAR), as seen by shortening of the contraction in Figure $1 B$ at shorter CLs. Figure $2 B-D$ show the average for the contraction timing parameters. Total contraction time, time to peak, and peak to $90 \%$ relaxation significantly decreased with shortening CL in newborn as well as in infant with no difference between age groups. Thus, although there is FDAR of the contraction at both ages, only infants show a positive FFR.

Developmental changes in calcium handling proteins. To begin to understand the mechanism of the flat FFR in the newborn human ventricle, we examined mRNA levels of the proteins NCX, SERCA, and PLB that are involved in SR calcium uptake (Fig. 3). In newborns, NCX mRNA is significantly larger than in infants $(p=0.003)$ whereas SERCA mRNA levels did not differ. In contrast, PLB mRNA levels and the PLB/SERCA ratio were smaller in newborns compared with infants.

We examined protein levels by western blot. Figure $4 A$ shows example NCX western blots. From left to right, samples are newborns, young infants (3-6 mo) and older infants (6-14 mo). Part B shows a significant negative correlation between NCX protein level and increasing age. Both newborns and young infants had significantly higher levels of NCX when compared with older infants (Fig. 4C). We also examined the protein levels of SERCA (Fig. $4 D-F$ ). Representative blots are shown in part D and linear regression analysis of SERCA as a function of age shows no relation (part E). There were no significant differences in the protein levels when we compared the three age groups (part F). In separate samples (using total protein), we examined the levels of PLB in newborn and older infants and did not find a difference between the two groups (parts $\mathrm{G}$ and $\mathrm{H}$ ). On the same blot, SERCA was also found to be unchanged. Additionally, the PLB/SERCA ratio did not change with age. The determination that SERCA protein levels do not change with
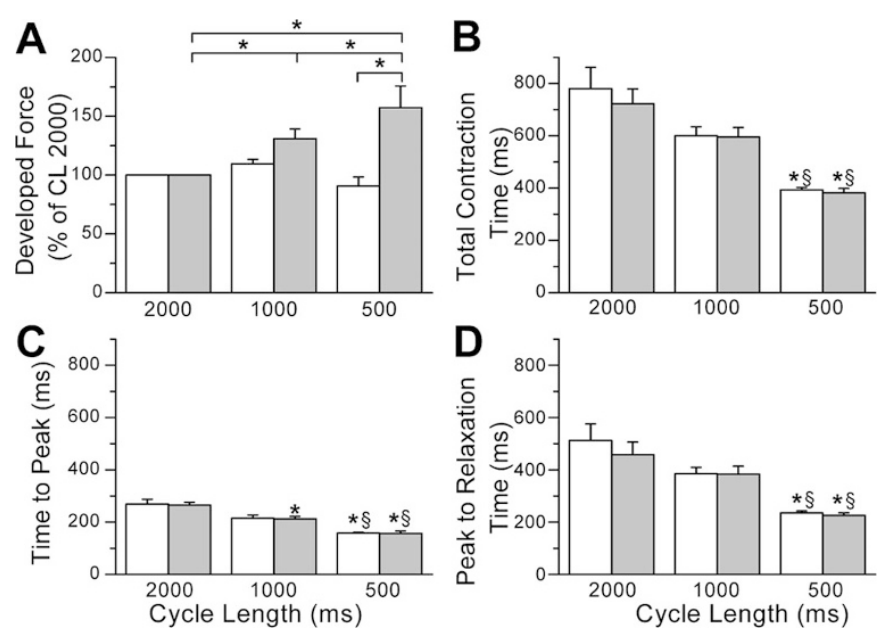

Figure 2. Average data for contractions from newborn and infant ventricular tissue strips are shown. A. Average developed force expressed as percent of CL $2000 \mathrm{~ms}$ for newborn (open, $n=7$, four patients) and infant (shaded, $n=$ 7 , six patients) ventricle $(* p<0.05)$. B. Total contraction time, $C$. Time to peak and $D$. Peak to $90 \%$ relaxation time for newborn (open) and infant (shaded) ventricular strips ( $* p<0.05$ compared with CL $2000 \mathrm{~ms} ;{ }^{\S} p<0.05$ compared with CL $1000 \mathrm{~ms}$ ).

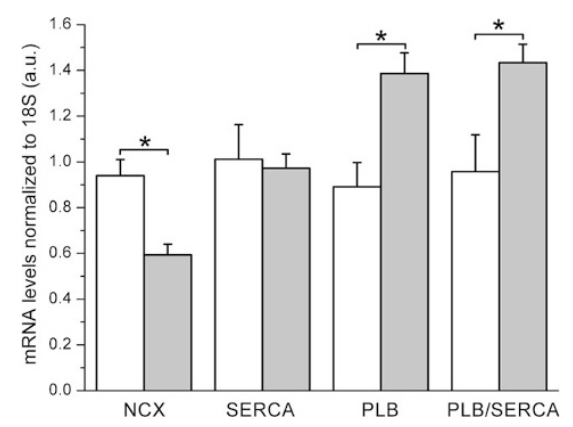

Figure 3. mRNA levels (normalized to $18 \mathrm{~S}$ rRNA) of calcium handling proteins change with developmental age. Newborn (open, $n=6$ ) and infant (shaded, $n=5$ ) levels of NCX (Na/Ca exchanger), SERCA (SR Ca-ATPase pump), and PLB (phospholamban) as well as the PLB/SERCA ratio are shown. ${ }^{*} p<0.05$.

development is consistent with mRNA results (Fig. 3). In contrast, the protein level of PLB and PLB/SERCA ratio did not vary with age, which differs from the mRNA results.

Immunostaining of NCX and SERCA proteins. We stained isolated ventricular cells from newborn and infant patients with di-8-ANNEPS and found that the cells from newborns (Fig. 5A, left) were smaller and lacked transverse (T)-tubules with staining only on the cell surface. Cells from infant ventricle (right) showed a more developed T-tubule system indicated with arrows. NCX staining (red) in a newborn cell (Fig. 5B, left) shows staining only on the periphery, consistent with the lack of T-tubules (Fig. 5A). In contrast, NCX is found in the T-tubules as well as the cell surface in infant cells (right). When we examined the localization of SERCA, we saw a regular striated pattern of staining (green, Fig. $5 C$ ) in both the newborn (left) and the infant (right) cells. For part C, the nuclei are stained red. Note that newborn cells were predominantly mononucleated whereas the infant cells had some mononucleated and some binucleated cells. The lack of 
A

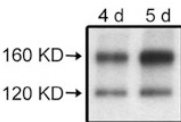

B

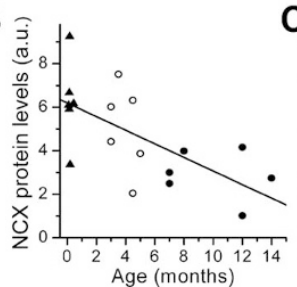

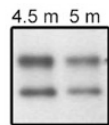

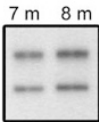

$\mathrm{C}_{\overline{\mathrm{j}}}$

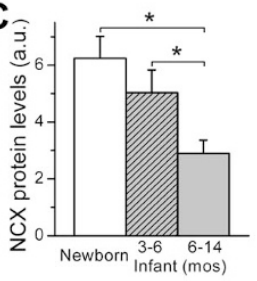

D

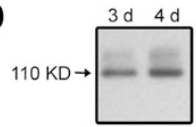

E

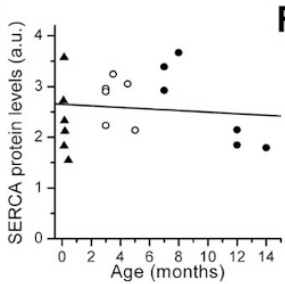

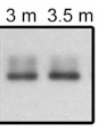

F

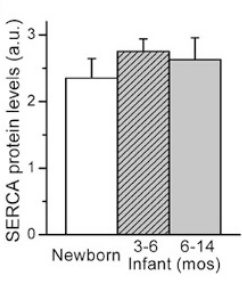

G

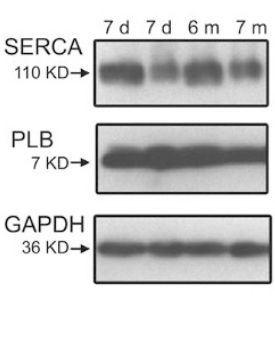

H

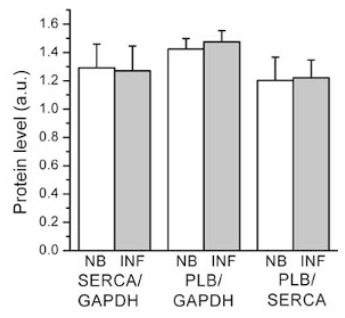

Figure 4. Protein levels of calcium handling proteins in the developing human ventricle. A. Example of western blots for NCX (Na/Ca exchanger). Lanes are labeled with age of patient (d, days; m, months) with newborns furthest left, young infants in the center and older infants furthest right. $B$. Density of NCX plotted as a function of age (newborns, solid triangles; young infants, open circles; older infants, solid circles), showing an inverse linear relationship $(R=-0.66, p=$ 0.003 ) between NCX protein levels and age. $C$. Average NCX protein levels for the three age groups: newborn (open, $n=6$ ), young infants (hashed and shaded, $n=6$ ) and older infants (shaded, $n=6$ ). ${ }^{*} p<0.05$. D. Western blots of SERCA (SR Ca-ATPase pump) labeled with ages as in (A). E. Density of SERCA plotted as a function of age $(\mathrm{R}=-0.11, p=$ n.s.). $F$. Average SERCA levels for the three age groups ( $n=6$ for each age). Parts $A-F$ used membrane proteins. $G$. Western blots using total proteins of SERCA, phospholamban (PLB) and GAPDH for loading control. $H$. Summary data for part $G$, normalized to GAPDH ( $n=6$ newborn and $n=5$ infant).
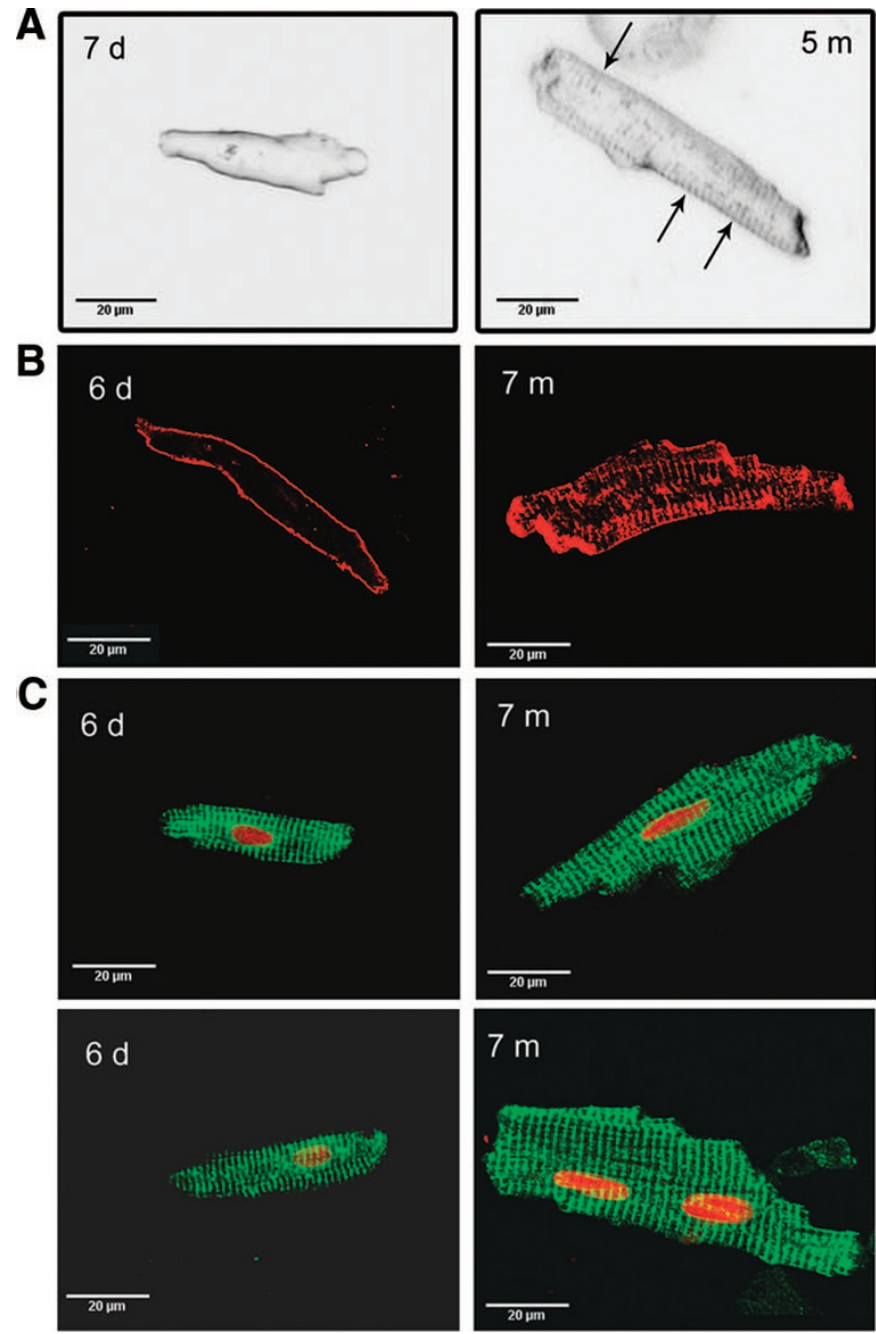

Figure 5. Morphologic analysis of ventricular cells isolated from ventricle from newborn and infant patients. A. Single ventricular cells from a newborn (left, $7 \mathrm{~d}$ ) and an infant (right, $5 \mathrm{mo}$ ) with the membrane of the cells labeled with di-8-ANNEPS. Arrows indicate partial T-tubule development in infant cell. $B$. Immunostaining of ventricular cells for $\mathrm{Na} / \mathrm{Ca}$ exchange $(\mathrm{NCX})$ in newborn (left, $6 \mathrm{~d}$ ) and infant (right, $7 \mathrm{mo}$ ). C. Immunostaining of newborn (left) and infant (right) ventricular cells with SR Ca-ATPase pump (SERCA, green) and nuclear staining (red).
T-tubules and mononucleated cells seen in the newborn are consistent with a more immature phenotype.

\section{DISCUSSION}

Very few studies have examined isometric contractions in very young human ventricular tissue. Developed force measured in ventricular strips from patients with TOF $(2.5-35 \mathrm{mo})$ was $\sim 1.0 \mathrm{mN}$ (1.5 mm wide tissue pieces) (5), which is qualitatively similar to the developed force we report in this study for infant human ventricle $\left(0.9 \pm 0.4 \mathrm{mN} / \mathrm{mm}^{2}\right)$. A major finding of this study is that newborn human ventricle has a flat FFR whereas the infant ventricle has a positive FFR (Figs. 1-2). Animal studies have shown a positive FFR in young mammalian ventricle but did not report changes in the FFR with development $(3,20)$. Comparing immature to adult rabbit papillary muscles, Artman et al. (4) showed a tendency for a smaller FFR in immature tissue, but this result did not reach statistical significance. Cheung et al. (6) measured force frequency curves in children with congenital heart defects with noninvasive measurements of contractility using tissue Doppler. They showed a positive FFR in both neonates with transposition of the great arteries with an average age of $11 \mathrm{~d}$ and in infants with TOF with an average age of $4.5 \mathrm{mo}$. The difference between that study and our work may be due to the younger age and different pathology of our newborn group or to differences in measurement methodology.

Many investigators have shown a blunted or negative FFR in heart failure $(7,8)$, similar to the differences in newborn and infant human ventricular strips in this study. The positive FFR seen in normal ventricle is likely due to increased calcium influx per unit time (via the L-type calcium channel), resulting in increased SR calcium load $(9,21)$. Decreased levels of SERCA, PLB, or the PLB/SERCA ratio have been associated with the blunted FFR seen in heart failure (10-12). A recent study by Quaile et al. (12) in ventricle from pulmonary artery banded felines showed the flat FFR was due to an inability of the SR to increase calcium load in response to increased frequency and was associated with decreased levels of SERCA, PLB, and phosphorylated PLB. In the developing 
rabbit, several studies have shown SERCA $(13,14)$ and PLB (2) increase with postnatal age. We show a similar increase in PLB mRNA and in the ratio of PLB/SERCA mRNA (Fig. 3). Low levels of PLB in newborn human ventricle may contribute to the flat FFR through depressed function of SERCA. In contrast, we show that the protein levels of SERCA and PLB do not change with age and recent studies in the rabbit have shown that calcium stored in the SR does in fact contribute significantly to the calcium required for contraction (22). Thus, additional studies are required to determine whether the function of the SR is impaired in the newborn human ventricle. Additionally, there is a balance between SR calcium uptake and extrusion of calcium into the extracellular space by NCX. Shifting this balance toward extrusion of calcium by NCX, which has also been implicated in the blunted FFR in heart failure, is associated with impaired SR function and with elevated NCX levels $(7,9)$. NCX mRNA and protein levels of newborn human ventricle are larger compared with infant ventricle (Figs. 3-4), consistent with other studies $(1,15)$. Thus, the newborn human ventricle may be more dependent on NCX extrusion to clear calcium from the cytosol, resulting in lower dependence on the SR, which may lead to the blunted FFR.

Changes in the FFR may also be due to alterations in myofilaments with development. $\alpha$-skeletal actin increases with postnatal development and may alter contractility (23). Shortly after birth, troponin I switches from the slow skeletal to the faster cardiac isoform which correlates with increases in tension and decrease in calcium sensitivity (24). Decreased calcium sensitivity with development has also been correlated with changes in isoforms of troponin T (25). Nassar et al. (26) suggested that the greater relative internal load compared with contractile elements in newborn ventricular cells may contribute to decreased contractility in the newborn rabbit. Thus, developmental changes in myofilaments and associated proteins may contribute to the depressed FFR seen in our newborn group. Further studies are needed to evaluate these differences as a mechanism for the flat FFR in the newborn human ventricle.

Note that we show that increasing pacing frequency accelerates relaxation of contraction in both newborn and infant human ventricle (Fig. 2). Others have shown that relaxation of the mammalian ventricle increases with development $(1,27)$ and may be due to increases in SERCA levels and activity $(13,14)$. It is possible that changes in relaxation rates were not seen in this study due to the limited age range of the two groups. In the adult, calcium/calmodulin-dependent kinase II (CamKII) may be involved in FDAR $(28,29)$, but the role of CamKII remains controversial (30). Recently, Huke and Bers (29) showed that the time course of FDAR is faster than the time course of CamKII-dependent phosphorylation of PLB and ryanodine receptor and conclude that neither underlies the mechanism of FDAR. An alternative mechanism for FDAR in newborn human may be shortening of action potential duration, which has been shown to contribute to enhanced relaxation (31). We have not recorded action potentials simultaneously with contractions in this study, but such work would provide important information as to the mechanism of FDAR in the newborn. An additional mechanism of FDAR could be increased extrusion of calcium by NCX due to calcium accumulation in the subsarcolemal space at higher frequencies of pacing, thus increasing the rate of the exchanger (32). Hasenfuss et al. (8) showed in a study of heart failure patients that ventricle from patients with little diastolic dysfunction had increased levels of NCX and unchanged SERCA levels and demonstrated FDAR. In contrast, ventricular tissue with diastolic dysfunction had unchanged NCX, decreased SERCA levels, and did not demonstrate FDAR. These results suggest that increased NCX levels seen in our newborn group may contribute to FDAR.

Postnatal changes in ventricular cellular morphology have been shown in several species. In newborn rabbit ventricular cells, T-tubules are sparse and are partially developed at $10 \mathrm{~d}$ after birth (33). Newborn human ventricular cells also have sparse T-tubules that develop over the first year of life (Fig. 5). In rabbit, T-tubule development correlates with development of a more spatially homogeneous calcium transient (33). Furthermore, several studies have shown that NCX is located only on the periphery in newborn rabbit cells and becomes more central and aligns with the T-tubules with postnatal development $(33,34)$. We show that NCX is found only on the periphery of the newborn human ventricular cells but has a more striated pattern in the infant cells. Furthermore, the spatial organization of SERCA was similar in both the newborn and infant cells and similar to that seen in adult rabbit (13). We also found that newborn human cells were primarily mononucleated, whereas infant cells had a mix of mono- and binucleated cells (Fig. 5C). Schmid and Pfitzer (35) found that near the time of birth in human right ventricle, only $11 \%$ of the cells were binucleated and that this increased to $42 \%$ by 1 y of age. Postnatal development has been shown to include a transformation from mononucleated to bi- or multinucleated myocytes (36).

We cannot definitively say that the changes in the FFR between newborn and infant ventricle are due to the different developmental ages of the patients and not due to the different dominant pathology of the two age groups (HLHS versus TOF). However, there are several pieces of evidence, mirroring work in other mammalian species that suggests that the difference in the FFR between newborns and infants is because of their different developmental age. In particular, we show a linear decrease in NCX levels from newborns to young infants to older infants (Fig. 4). Furthermore, we show development of T-tubules and appearance of binucleated cells with increasing age (Fig. 5).

In summary, we have shown for the first time that the newborn human ventricle has a blunted FFR that improves during the early postnatal period. The blunted FFR may be due to decreased SR calcium load due to competition between NCX and SERCA for clearing calcium from the cytoplasm. The level of NCX is higher in the newborn compared with the infant and cellular changes between the newborn and infant human ventricle and are consistent with those seen in animal models of development. A better understanding of developmental changes in contractility in human ventricle is critically important for developing therapies that are specific for the pediatric cardiac patient. In particular, as pediatric cardiac 
surgery is increasingly done in the first year of life, with concomitant issues of arrhythmias and ventricular failure, the need for understanding calcium regulation in this age group is becoming increasingly important.

\section{REFERENCES}

1. Schiffmann H, Flesch M, Hauseler C, Pfahlberg A, Bohm M, Hellige G 2002 Effects of different inotropic interventions on myocardial function in the developing rabbit heart. Basic Res Cardiol 97:76-87

2. Szymanska G, Grupp IL, Slack JP, Harrer JM, Kranias EG 1995 Alterations in sarcoplasmic reticulum calcium uptake, relaxation parameters and their responses to beta-adrenergic agonists in the developing rabbit heart. J Mol Cell Cardiol 27:18191829

3. Klautz RJ, Baan J, Teitel DF 1997 The effect of sarcoplasmic reticulum blockade on the force/frequency relationship and systolic contraction patterns in the newborn pig heart. Pflugers Arch 435:130-136

4. Artman M, Graham TP Jr, Boucek RJ Jr 1985 Effects of postnatal maturation on myocardial contractile responses to calcium antagonists and changes in contraction frequency. J Cardiovasc Pharmacol 7:850-855

5. Molenaar P, Bartel S, Cochrane A, Vetter D, Jalali H, Pohlner P, Burrell K, Karczewski P, Krause EG, Kaumann A 2000 Both beta(2)- and beta(1)-adrenergic receptors mediate hastened relaxation and phosphorylation of phospholamban and troponin I in ventricular myocardium of Fallot infants, consistent with selective coupling of beta(2)-adrenergic receptors to G(s)-protein. Circulation 102:1814-1821

6. Cheung MM, Smallhorn JF, Vogel M, Van AG, Redington AN 2006 Disruption of the ventricular myocardial force-frequency relationship after cardiac surgery in children: noninvasive assessment by means of tissue Doppler imaging. J Thorac Cardiovasc Surg 131:625-631

7. Pieske B, Trost S, Schutt K, Minami K, Just H, Hasenfuss G 1998 Influence of forskolin on the force-frequency behavior in nonfailing and end-stage failing human myocardium. Basic Res Cardiol 93:66-75

8. Hasenfuss G, Schillinger W, Lehnart SE, Preuss M, Pieske B, Maier LS, Prestle J, Minami K, Just H 1999 Relationship between $\mathrm{Na}+-\mathrm{Ca} 2$ +-exchanger protein levels and diastolic function of failing human myocardium. Circulation 99:641-648

9. Bers DM 2001 Control of Cardiac Contraction by SR and Sarcolemmal Ca Fluxes. Excitation-Contraction Coupling and Cardiac Contractile Force. Kluwer Academic Publishers, Dordrecht, pp 245-272

10. Hasenfuss G, Meyer M, Schillinger W, Preuss M, Pieske B, Just H 1997 Calcium handling proteins in the failing human heart. Basic Res Cardiol 92:87-93

11. Meyer M, Bluhm WF, He H, Post SR, Giordano FJ, Lew WY, Dillmann WH 1999 Phospholamban-to-SERCA2 ratio controls the force-frequency relationship. Am J Physiol 276:H779-H785

12. Quaile MP, Rossman EI, Berretta RM, Bratinov G, Kubo H, Houser SR, Margulies KB 2007 Reduced sarcoplasmic reticulum $\mathrm{Ca}(2+)$ load mediates impaired contractile reserve in right ventricular pressure overload. J Mol Cell Cardiol 43:552-563

13. Chen F, Ding S, Lee BS, Wetzel GT 2000 Sarcoplasmic reticulum Ca(2+)ATPase and cell contraction in developing rabbit heart. J Mol Cell Cardiol 32:745-755

14. Fisher DJ, Tate CA, Phillips S 1992 Developmental regulation of the sarcoplasmic reticulum calcium pump in the rabbit heart. Pediatr Res 31:474-479

15. Qu Y, Ghatpande A, El-Sherif N, Boutjdir M 2000 Gene expression of $\mathrm{Na}^{+} / \mathrm{Ca}^{2+}$ exchanger durig development in human heart. Cardiovasc Res 45:866-873

16. Qu Y, Boutjdir M 2001 Gene expression of SERCA2a and L- and T-type Ca channels during human heart development. Pediatr Res 50:569-574
17. Tipparaju SM, Kumar R, Wang Y, Joyner RW, Wagner MB 2004 Developmental differences in L-type calcium current of human atrial myocytes. Am J Physiol Heart Circ Physiol 286:H1963-H1969

18. Bradford MM 1976 A rapid and sensitive method for quantitation of microgram quantities of protein utilizing the principle of protein-dye binding. Anal Biochem 72:248-254

19. Brattelid T, Tveit K, Birkeland JA, Sjaastad I, Qvigstad E, Krobert KA, Hussain RI, Skomedal T, Osnes JB, Levy FO 2007 Expression of mRNA encoding G proteincoupled receptors involved in congestive heart failure-a quantitative RT-PCR study and the question of normalisation. Basic Res Cardiol 102:198-208

20. Vornanen M 1992 Force-frequency relationship, contraction duration and recirculating fraction of calcium in postnatally developing rat heart ventricles: correlation with heart rate. Acta Physiol Scand 145:311-321

21. Endoh M 2004 Force-frequency relationship in intact mammalian ventricular myocardium: physiological and pathophysiological relevance. Eur J Pharmaco 500:73-86

22. Huang J, Hove-Madsen L, Tibbits GF 2008 Ontogeny of $\mathrm{Ca} 2+$-induced $\mathrm{Ca} 2+$ release in rabbit ventricular myocytes. Am J Physiol Cell Physiol 294:C516-C525

23. Marston SB, Redwood CS 2003 Modulation of thin filament activation by breakdown or isoform switching of thin filament proteins: physiological and pathological implications. Circ Res 93:1170-1178

24. Kruger M, Kohl T, Linke WA 2006 Developmental changes in passive stiffness and myofilament $\mathrm{Ca} 2+$ sensitivity due to titin and troponin-I isoform switching are not critically triggered by birth. Am J Physiol Heart Circ Physiol 291:H496-H506

25. Nassar R, Malouf NN, Kelly MB, Oakeley AE, Anderson PA 1991 Force-pCa relation and troponin $\mathrm{T}$ isoforms of rabbit myocardium. Circ Res 69:1470-1475

26. Nassar R, Reedy MC, Anderson PA 1987 Developmental changes in the ultrastructure and sarcomere shortening of the isolated rabbit ventricular myocyte. Circ Res 61:465-483

27. Artman M, Kithas PA, Wike JS, Strada SJ 1988 Inotropic responses change during postnatal maturation in rabbit. Am J Physiol 255:H335-H342

28. Bassani RA, Mattiazzi A, Bers DM 1995 CaMKII is responsible for activitydependent acceleration of relaxation in rat ventricular myocytes. Am J Physiol 268:H703-H712

29. Huke S, Bers DM 2007 Temporal dissociation of frequency-dependent acceleration of relaxation and protein phosphorylation by CaMKII. J Mol Cell Cardiol 42:590599

30. Kassiri Z, Myers R, Kaprielian R, Banijamali HS, Backx PH 2000 Rate-dependent changes of twitch force duration in rat cardiac trabeculae: a property of the contractile system. J Physiol 524:221-231

31. Pieske B, Kretschmann B, Meyer M, Holubarsch C, Weirich J, Posival H, Minami K, Just H, Hasenfuss G 1995 Alterations in intracellular calcium handling associated with the inverse force-frequency relation in human dilated cardiomyopathy. Circulation 92:1169-1178

32. Weber CR, Ginsburg KS, Philipson KD, Shannon TR, Bers DM 2001 Allosteric regulation of $\mathrm{Na} / \mathrm{Ca}$ exchange current by cytosolic $\mathrm{Ca}$ in intact cardiac myocytes. J Gen Physiol 117:119-131

33. Haddock PS, Coetzee WA, Cho E, Porter L, Katoh H, Bers DM, Jafri MS, Artman M 1999 Subcellular [Ca2+]i gradients during excitation-contraction coupling in newborn rabbit ventricular myocytes. Circ Res 85:415-427

34. Dan P, Lin E, Huang J, Biln P, Tibbits GF 2007 Three-dimensional distribution of cardiac $\mathrm{Na}+-\mathrm{Ca} 2+$ exchanger and ryanodine receptor during development. Biophys J 93:2504-2518

35. Schmid G, Pfitzer P 1985 Mitoses and binucleated cells in perinatal human hearts Virchows Arch B Cell Pathol Incl Mol Pathol 48:59-67

36. Ahuja P, Sdek P, MacLellan WR 2007 Cardiac myocyte cell cycle control in development, disease, and regeneration. Physiol Rev 87:521-544 